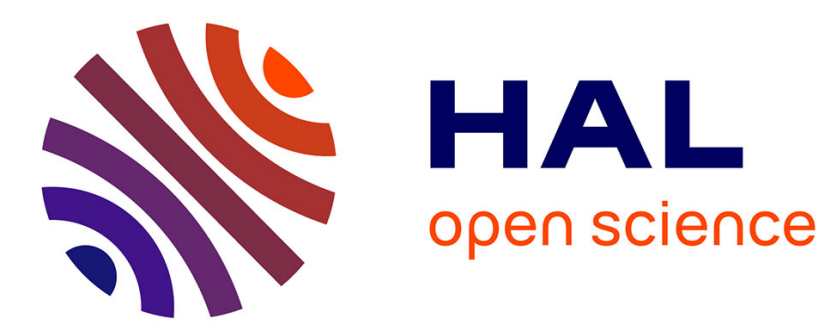

\title{
Vascular normalization: a real benefit?
}

Domenico Ribatti

\section{To cite this version:}

Domenico Ribatti. Vascular normalization: a real benefit?. Cancer Chemotherapy and Pharmacology, 2011, 68 (2), pp.275-278. 10.1007/s00280-011-1683-z . hal-00703553

\section{HAL Id: hal-00703553 \\ https://hal.science/hal-00703553}

Submitted on 3 Jun 2012

HAL is a multi-disciplinary open access archive for the deposit and dissemination of scientific research documents, whether they are published or not. The documents may come from teaching and research institutions in France or abroad, or from public or private research centers.
L'archive ouverte pluridisciplinaire HAL, est destinée au dépôt et à la diffusion de documents scientifiques de niveau recherche, publiés ou non, émanant des établissements d'enseignement et de recherche français ou étrangers, des laboratoires publics ou privés. 


\title{
MS CCP-11-0203-REVISED
}

\section{MINI-REVIEW}

\section{Vascular normalization: a real benefit?}

\author{
Domenico Ribatti
}

Department of Human Anatomy and Histology, University of Bari Medical School, Bari, Italy

\section{Corresponding Author}

Prof. Domenico Ribatti

Department of Human Anatomy and Histology

University of Bari Medical School

Piazza G. Cesare, 11

Policlinico

70124 Bari (Italy)

Phone +39.080 .5478326$

Fax. $\quad+39.080 .5478310$

Email ribatti@anatomia.uniba.it 


\begin{abstract}
It is well established that antibodies to vascular endothelial growth factor (VEGF) in combination with chemotherapeutic agents produce synergistic cytotoxicity in a range of cancer. In this review article it has been analyzed if the so called "vascular normalization" of abnormal tumor blood vessels as an effect of VEGF inhibition in association with chemotherapeutic agents in the treatment of tumors, produces a real benefit. Literature data show that the process of normalization of the structure of tumor blood vessels is not always accompained with a real benefit. In fact as in the case of cerebral tumors, the process of normalization may induce a re-establishment of the low permeability characteristics of normal brain microvasculature, preventing the delivery of chemotherapeutics.
\end{abstract}

Keywords: angiogenesis; antiangiogenesis; chemotherapy; vascular normalization; VEGF. 


\section{Introduction}

The introduction of chemotherapy in 1950-60 has resulted in the development of curative therapeutic interventions for patients with several types of advanced solid and hematologic tumors [1, Marchall, 1964].

In 1971, Judah Folkman published in the "New England Journal of Medicine" a hypothesis that tumor growth is angiogenesis-dependent and that inhibition of angiogenesis could be therapeutic [2]. This article also introduced the term antiangiogenesis to mean the prevention of new vessel sprouts from being recruited by a tumor. In the last 35 years, it has been estimated that more than 200 companies have worked and are still working in the area of angiogenesis and several of the compounds that modulate angiogenesis are currently being evaluated in clinical trials.

It is well established that antibodies to vascular endothelial growth factor (VEGF) in combination with chemotherapeutic agents produce synergistic cytotoxicity in a range of cancer. Bevacizumab is a humanized monoclonal antibody that neutralizes one of the biological active forms of VEGF, VEGF-A. It appears that bevacizumab can be a component of an effective combination therapy approach to colorectal cancer, non-small-cell-lung cancer (NSCLC), and breast cancer [3-5]. Encouraging results have also been obtained when chemotherapy has been used in combination with an anti-VEGF receptor-2 (VEGFR-2) monoclonal antibody (cediranib) [6] and an oral tyrosine kinase inhibitor of VEGFRs and epidermal growth factor receptor (EGFR) (vandetanib) [7, 8]. The observation that combining chemotherapy with angiogenesis inhibitors causes increased apoptosis in tumors in vivo $[9,10]$ suggest that angiogenesis inhibitors may have an additive effect when administered in combination with chemotherapy.

The aim of this review article is to analyze if the so called "vascular normalization" of abnormal tumor blood vessels as an effect of VEGF inhibition, generally used in association with conventional chemotherapeutic agents in the treatment of tumors, produces a real benefit

\section{Morpho-functional properties of tumor blood vessels}


Tumor blood vessels are irregular in size, shape, and branching pattern, lack the normal hierarchy and do not display the recognizable features of arterioles, capillaries or venules [11]. Tumor-associated endothelium is structurally defective: intercellular gaps, transendothelial holes, vesiculo-vacuolar organelles, and endothelial fenestrae are present in the endothelium of tumor vessels [12].

Defects in endothelial cells barrier function, due to abnormal cell-cell junctions and other changes, are responsible of vascular leakiness, which has been attributed also to highly active angiogenesis and microvascular remodeling. Leakiness correlates with histological grade and malignant potential [13] and can be exploited in locating tumors by imaging contrast media and in the delivery of macromolecular therapeutics [14]. Furthermore, it results in extravasation of plasma proteins and even erythrocytes and may facilitate the traffic of tumor cells into the bloodstream and the formation of metastases [13].

Whereas endothelial cells of mature, quiescent vessels are characteristically low proliferative and their estimated turnover times are measured in years, those of tumor vessels are markedly dependent on growth factors for survival. VEGF plays a central role in the induction of host vessels into a growing tumor. When endothelial cells invade a newly formed tumor, they come into contact with tumor cells that produce VEGF, which may be responsible not only for vascular proliferation, but also for the altered permeability of the newly formed vessels $[15,16]$. Although tumor cells represent the major source of VEGF, tumor-associated stroma is also an important site of VEGF production [17].

\section{The concept of "normalization" and the role of VEGF inhibition}

Excess production of pro-angiogenic factors and/or diminshed production of anti-angiogenic molecules may be considered responsible of the vascular structure anomalies in tumors [18]. Restore of this balance may induce a normalization of structure of blood vessels. The concept of "normalization" of tumor blood vessels by antiangiogenic drugs was introduced by Rakesh Jain in 
2001 [19]. The state of normalization is probably transient, and dependent on the dose and duration of the treatment.

VEGF inhibition could temporarily restore or normalize the function of tumor-associated vasculature, decreasing vascular permeability in conjunction with restoration of sustained pressure gradients, as demonstrated by intravital imaging studies in preclinical models and in cancer patients [20], thereby enhancing systemic delivery of oxygen or perfusion of cytotoxic agents to intratumoral sites [21, 22]. Moreover, abrogation of VEGF signaling increases collagenase IV activity, leading to restoration of normal basement membrane [23], which generally in tumors has an abnormally thickness [24].

Temporal vascular nomalization induces vascular regression, which causes tumor hypoxia [25]. Hypoxia could alter the property of cancer cells through the induction of hypoxia inducible factor-1 (HIF-1), as HIF-1 is reported to be involved in the induction of genes that induce invasive and metastatic properties of tumor cells [26]. Hypoxia generated by angiogenesis inhibition triggers pathways that make tumors more aggressive and metastatic and less sensitive to antiangiogenic treatment, as demosntrated by Paez-Ribes et al. [27], who used blocking VEGFR-2 antibodies to mouse models of pancreatic neuroendocrine carcinoma and glioblastoma, and found that cancers showed heightned invasiveness or metastasis

\section{Vascular normalization increases pericyte coverage}

Pericytes of tumor vessels have an abnormally loose association with endothelial cells, have an irregular shape and cytoplasmic projections into the tumor parenchyma [28]. Irregularities in their coverage correlate with increased vascular permeability and less effective vascular delivery [29].

Pericytes are believed to protect the remaining vessels and defend against the anti-VEGF treatment [30]. Blockade of VEGFR-2 has been shown to increase total pericyte vasculature. In fact, blockade of VEGF signaling promotes pericyte recruitment in Lewis lung carcinomas, RIP- 
Tag-2 tumors [31] and other tumor models [21, 32], by triggering increased tumor production of angiopoietin-1 (Ang-1) [23]. Surviving blood vessels of RIP-Tag-2 tumors treated with anti-VEGF agents have a reduced expression of VEGFR-2 and VEGFR-3 in addition to a more normal caliber [29]. More recently, Helfrich et al. [33] demonstrated in spontaneoulsy developing melanomas of MT/ret transgenic mice after using anti-VEGF therapy and in human melanoma metastases taken at clinical relapse in patients undergoing adjuvant treatment with bevacizumab, that tumor vessels which are resistant to anti-VEGF therapy are characterized by enhanced vessel diameter and normalization of the vascular bed by coverage of mature pericytes.

\section{The controversial effect of vascular normalization in the treatment of cerebral tumors}

Bevacizumab is currently involved in a broad development program with more than 100 ongoing clinical trials in various indications and has been approved by the Food and Drug Administration (FDA) for treatment of recurrent glioblastoma [34]. Bevacizumab prolongs progression-free survival and controls peritumoral edema, but its effects on overall survival remain to be determined. The decrease of brain edema due to vascular normalization is thought to be an important factor of its benefit [35].

Other inhibitors of VEGF, VEGFRs and other proangiogenic signaling pathways are being evaluated. MRI scans showed that treatment with cediranib (AZ 2171), a small molecule inhibitor of VEGFRs, lowered blood vessel size and permeability, consistent with the hypothesis of vascular normalization [36]. Cediranib monotherapy was used in a clinical trial for recurrent glioblastoma with encouraging radiographic response and 6-month progression-free survival [37]. Sorensen et al. [38] evaluated after a single dose of cediranib the correlation between clinical outcome in glioblastoma patients and MRI changes in vascular permeability/flow and in microvessel outcome, and the change of circulating collagen IV levels, They demonstrated that the changes in these parameters and their combination in a "vascular normalization index" correlate with duration of overall survival and/or progression-free survival. 
The inhibitors of VEGF in the therapy of central nervous system malignancy normalizes tumor vasculature and decrease tumor interstitial pressure, leading to an improved access of cytoreductive drugs and radiotherapy efficacy, due to an increased oxygen delivery [39]. However, these agents may also restore the low permability characteristics of normal brain microvasculature, counteracting beneficial effects. The presence of an intact blood-brain barrier in some areas of the tumor and the presence of a partially functional blood-brain barrier in other areas of the tumor can prevent the delivery of therapeutic compounds.

\section{The interplay between the effects of VEGF inhibition and angiopoietins in normalization}

VEGFR-2 blockade can lead to the upregualtion of Ang-1 that increase pericyte coverage of the vessels [23]. Ang-2 plays a more important role in tumor angiogenesis than it does in normal angiogenesis. As an antagonist for Ang-1, it is responsible for blood vessel destabilization in vasculature surrounding tumors.

In glioblastoma patients, the Ang-1/Ang-2 ratio correlates with survival [40] and vascular normalization [37], whereas high Ang-2 levels correlate with resistance to anti-VEGF therapy [37]. Moreover, blockade of VEGF signaling with the VEGFR tyrosine kinase inhibitor cediranib significantly reduced levels of Ang-2 in some patients, even if the decrease was transient and modest [37].

Chae et al. [41] expressed Ang-2 in an orthotopic glioma model and demonstrated that ectopic expression of Ang-2 had no effect on vascular permeability, tumor growth, or survival, but it resulted in higher vascular density, with dilated vessels and reduced mural cell coverage. When combined with anti-VEGFR-2 treatment, Ang-2 destabilized vessels and compromised the survival benefit of VEGFR-2 inhibition by increasing vascular permeability, suggesting that VEGFR-2 inhibition normalized tumor vasculature, whereas ectopic expression of Ang-2 diminshed the beneficial effects of VEGFR-2 blockade by inhibiting vessel normalization. 


\section{Concluding remarks}

A number of studies have demonstrated the validity and clinical benefit of inhibiting angiogenesis in various types of cancer. However, as it has been clarified in this article, it should be considered that the process of normalization of the structure of tumor blood vessels as a consequence of the use of anti-VEGF antibodies, is not always accompained with a real benefit. In fact as in the case of cerebral tumors, the process of normalization may induce a re-establishment of the low permeability characteristics of normal brain microvasculature, preventing the delivery of chemotherapeutics.

\section{Conflict of interest}

No conflict of interest to declare.

\section{Acknowledgements}

Supported in part by AIRC, Milan, Italy.

\section{Contributions}

D.R. wrote the manuscript. 


\section{References}

1. Marchall EK Jr (1964) Historical perspectives in chemotherapy. Adv Chemother 13: 1-8.

2. Folkman J (1971) Tumor angiogenesis: therapeutic implications. N Engl J Med 285: 1182-1186.

3. Hurwitz F, Fehrenbacher L, Novotny W, et al. (2004) Bevacizumab plus irinotecan, and leucovurin for metastatic colorectal cancer. N Engl J Med 350: 2335-2342.

4. Miller K, Wang M, Gralow J et al. (2007) Paclitaxel plus bevacizumab versus paclitaxel alone for metastatic breast cancer. N Engl J Med 357: 2666-2676.

5. Sandler A, Gray R, Perry MC et al (2006) Paclitaxel-carboplatin alone or with bevacizumab for non-small-cell lung cancer. N Engl J Med 355: 2542-2550.

6. Goss G, Arnold A, Shepherd F et al (2010) Randomized, double-blind trial of carboplatin and paclitaxel with either oral cediranib or placebo in advanced non-small cell lung cancer. NCIC clinical trial group BR24 study. J Clin Oncol 28: 49-55.

7. Herbst R, Sun Y, Korfee S, et al., 2009. Vandetanib plus docetaxel versus docetaxel as secondline treatment for patients with advanced non-small cell lung cancer (NSCLC): a randomized, double-blind phase III trial (ZODIAC). J Clin Oncol, 27: Abstr CRA8003.

8. De Boer R, Arrieta O, Gottbried M et al (2009) Vandetanib plus pemetrexed versus pemetrexed as second-line therapy in patients with advanced non-small cell lung cancer (NSCLC): a randomized, double-blind phase III trial (ZEAL). J Clin Oncol 27: Abstr 8010.

9. Inoue K, Chikazawa M, Fukata S, Yoshikawa C, Shuin T (2003) Docetaxel enhances the therapuetic effect of the angiogenesis inhibitor TNP-470 (AGM-1470) in metastatic human transitional cell carcinoma. Clin Cancer Res 9: 886-899.

10. Song S, Wientijes MG, Walssh C, Au JL (2001) Nontoxic doses of suramin enhance activity of paclitaxel against lung metastases. Cancer Res 61: 6145-6150. 
11. Ribatti D, Nico B, Crivellato E, Vacca A (2007) The structure of the vascular network of tumors. Cancer Letters 248: 18-23.

12. Dvorak HF, Nagy JA, Dvorak JT, Dvorak AM (1988) Identification and characterization of the blood vessel of solid tumors that are leaky to circulating macromolecules. Am J Pathol 133: 95-109. 13. Daldrup D, Shames DM, Wendland M, Okuhata Y, Link TM, Rosenau W, et al (1998) Correlation of dynamic contrast-enhanced MR imaging with histologic tumor grade: comparison of macromolecular and small-molecular contrast media. Am J Roentgenol 171: 941-949.

14. Mc Donald DM, Choyke PL (2003) Imaging of angiogenesis: from microscope to clinic. Nat Med 9: 713-725.

15. Senger DR, Brown L, Claffey K, Dvoark A (1995) Vascular permeability factor, tumor angiogenesis and stroma generation. Invasion Metastasis 14: 385-394.

16. Dvorak HK, Harvey VS, Estrella P, Brown LF, Mc Donagh J, Dvorak AM (1987) Fibrin containing gels induce angiogenesis: implications for tumro stroma generation and wound healing. Lab Invest 57: 673-686.

17. Fukumura D, Sjoblom T, Abramsson A, Ellingsen J, Micke P, Li H et al (1998) Tumor induction of VEGF promoter activity in stromal cells. Cell 94: 715-725.

18. Ribatti D, Nico B, Crivellato E, Roccaro AM, Vacca A (2007) The history of the angiogenic switch concept. Leukemia 21: 44-52.

19. Jain RK (2001) Normalizing tumor vasculature with anti-angiogenic therapy: a new paradigm for combination therapy. Nat Med 7: 987-989.

20. Fukumura D, Duda DG, Munn LL, Jain RK (2010) Tumor microvasculature and microenvironment: novel insights through intravital imaging in pre-clinical models. Microcirculation 17: 206-225.

21. Tong RT, Boucher Y, Kozin SV, Winkler F, Hicklin DJ, Jain RK (2004) Vascular normalization by vascular endothelial growth factor receptor 2 blockade induces a pressure gradient across the vasculature and improves drug penetration in tumors. Cancer Res 64: 3731-3736. 
22. Jain RK (2005) Normalization of tumor vasculature: an emerging concept in antiangiogenic therapy. Science 307: 58-62.

23. Winkler F, Kozin SV, Tong RT, Chae SS, Booth MF, Garkavstev I, et al (2004) Kinetics of vascular normalization by VEGFR2 blockade governs brain tumor response to radiation: role of oxygenation, angiopoietin-1 and matrix metalloproteinases. Cancer Cell 6: 553-563.

24. Baluk P, Morikawa S, Haskell A, Mancuso M, Mc Donald DM (2003) Abnormalities of basement membrane on blood vessels and endothelial sprouts in tumors. Am J Pathol 163: 1801-15. 25. Sato Y (2011) Persistent vascular normalization as an alternative goal of anti-angiogenic cancer therapy. Cancer Sci doi: 10.1111/j.1349-7006.2011.01929.x. [Epub ahead of print]

26. Semenza GL (2003) Targeting HIF-1 for cancer therapy. Nat Rev Cancer 3: 721-732.

27. Paez-Ribes M, Allen A, Hudock J, Takeda T, Okuyama H, Vinals F, et al (2009) Antiangiogenic therapy elicits malignant progression of tumors to increased local invasion and distant metastasis. Cancer Cell 15 222-231.

28. Morikawa S, Baluk P, Kaidoh T, haskell A, Jain RK, Mc Donald DM (2002) Abnormalities in pericytes on blood vessels and endothelial sprouts in tumors. Am J Pathol 160: 985-1000.

29. Ribatti D, Nico B, Crivellato E (2011) The role of pericytes in angiogenesis. Int J Dev Biol [Epub ahead of print].

30. Bergers G, Song S, Meyer-Morse N, Bergland E, Hanahan D (2003) Benefits of targeting both pericytes and endothelial cells in the tumor vasculature with kinare inhibitors. J Clin Invest 111: 1287-1295.

31. Inai T, Mancuso M, Hashizume H, Baffert F, Haskell A, Baluk P et al (2004) Inhibition of vascular endothelial growth factor (VEGF) signaling in cancer causes loss of endothelial fenestrations, regression of tumor vessels, and appearance of basement membrane ghosts. Am J Pathol 165: 35-52. 
32. Willett CG, Boucher Y, di Tomaso E, Duda DG, Munn LL, Tong RT, et al (2004) Direct evidence that the VEGF-specific antibody bevacizumab has antivascular effects in human rectal cancer. Nat Med 10: 145-147.

33. Helfrich I, Scheffrahn I, Bartling S, Weis J, von Felbert V, Middleton M, et al (2010) Resistance to antiangiogenic therapy is directed by vascular phenotype, vessel stabilization, and maturation in malignant melanoma. J Exp Med 207: 491-503.

34. Norden AD, Drappatz J, Wen PY (2009) Antiangiogenic therapies for high-grade glioma. Nat Rev Neurol 5: 610-620.

35. Martin V, Liu D, Gomez-Manzano C (2009) Encountering and adavancing through antiangiogenic therapy for gliomas. Curr Pharm Des 15: 353-364.

36. Batchelor TT, Sorensen AG, di Tomaso E, Zhang Wt, Duda DG, Cohen KS et al (2007) AZD2171, a pan VEGF receptor tyrosine kinase inhibitor normalizes tumor vasculature and alleviates edema in glioblastoma patients. Cancer Cell 11: 83-95.

37. Batchelor TT, Duda DG, di Tomaso E, Ancukiewicz M, Plotkin SR, Gerstner E et al (2010) Phase II study of cediranib, an oral pan-vascular endothelial growth factor receptor tyrosine kinase inhibitor, in patients with recurrent glioblastoma. J Clin Oncol 2010; 28: 2817-2823.

38. Sorensen AG, Batchelor TC, Zhang WT, Chen PJ, Yeo P, Wang M et al (2009) A "vascular normalization index" as a potential mechanistic biomarker to predict survival after a single dose od cediranib in recurrent glioblastoma patients. Cancer Res 69: 5296-5300.

39. McGee MC, Hammer JB, Willimas RF, Rosati SF, Sims TL, Ng CY et al (2010) Improved intratumoral oxygenation through vascular normalization increases glioma sensitivity to ionizing radiation. Int J Radiat Oncol Biol Phys 76: 1537-1545.

40. Sie M, Wagemakers M, Molem G, Mooij JJ, de Bont ES, den Dunner WF (2009) The angiopoietin-1/angiopoietin-2 balance as a prognostic marker in primary glioblastoma multiforme. $\mathrm{J}$ Neurosurg110: 147-155. 
41. Chae SS, Kamoun WS, Farrar CT, et al (2010) Angiopoietin-2 interferes with anti-VEGFR2induced vessel normalization and survival benefit in mice bearing gliomas. Clin Cancer Res 16: $3618-3627$. 